[DOI: 10.24214/jecet.A.10.3.36981.]

Juurnal of Enviranmental Science, Computer Science and Engineering \& Technology

\author{
An International Peer Review E-3 Journal of Sciences and Technology
}

Available online at www.jecet.org

Section A: Environmental Science

Review Article

\title{
Biogas Technology in Kenya: A Review
}

\author{
Lumadede H.M.*, Wangai L., Kwach S., Khalifa J. and Mbithi V. \\ Energy Research Division, Department of Research Technology and Innovation, Kenya Industrial \\ Research \& Development Institute, P. O. Box 30650-00100, Nairobi, Kenya
}

Received: 15 June 2021; Revised: 07 July 2021; Accepted: 22 July 2021

\begin{abstract}
Research into biogas production and sustainability in Kenya is in progress at Kenya Industrial Research and Development Institute (KIRDI) through its biogas laboratory. Biogas production is one of the renewable energies which we use in Kenya. Biogas importance, development, opportunities and the economical and sustainability in Kenya are discussed. The full exploitation of Kenya 's agricultural potential will yield a lot of biomass through which innovative use of the available bio waste from maize, cotton, tea and sugarcane can be utilized. Present and emerging biogas technologies convert these biowaste into renewable energy, thereby replacing the expensive fossil energy sources, and reducing dependency on fossil fuels. Other substrates like water hyacinth and molasses distillery waste have been found to be a good source of biogas. This review examines the energy potential of biogas production from crop residues. The findings will promote biogas addition to the energy mix Kenya needs as well as providing approaches, achievements, lessons learnt and other relevant aspects of domestic biogas programmers. It aims to achieve a greater, more effective use of biogas and contributes to the process by providing knowledge of biogas use in Kenya and its potential. Development partners-are supporting the implementation of market-based domestic biogas programmers in Kenya with a view to establish a commercially viable biogas sector.
\end{abstract}

Keywords: biogas, bio waste, energy, sustainability 


\section{INTRODUCTION}

Biogas technology is one of the viable renewable sources of energy for supplying clean and 4sustainable energy resulting from biological breakdown of organic compounds like leaf, rice straw, animal or human excreta, biodegradable waste or energy crop in a biogas plant in absence of oxygen. A biogas plant is also called digester and the reaction and interactions among the inputs fed is called digestion. Such plants produce 50-70 per cent methane that may be used for cooking, heating, lighting and may generate either mechanical or electrical power to some extent ${ }^{[1]}$. It also generates a residual called 'slurry' which may be used as fertilizer. It offers various benefits such as saving fuel wood and protecting forests as well as reduces expenditure on fuels. It further reduces household labor on time spent on cooking and housekeeping and improves hygienic conditions ${ }^{[2]}$. Kiplagat et al. ${ }^{[3]}$ found out that a large potential exists for the development of biomass based energy such as biogas, biodiesel and power generation form biogases.

Kenya is endowed with plenty of biomass reserves that are considered as a potential for anaerobic digestion. An analysis of the national energy shows heavy dependency on wood fuel and other biomass that account for $68 \%$ of the total energy consumption (petroleum $22 \%$, electricity $9 \%$, others account for $1 \%$ ).In this regard therefore, the Kenyan government through the Ministry of energy has been promoting and disseminating biogas technology as one of the renewable energy sources. These efforts were meant to encourage households to adopt other sources of energy and move away from traditional forms of energy like firewood which have devastating effects on the environment and people's health ${ }^{[4]}$. Under the new constitution of 2010, the County governments have been given a mandate to regulate energy. County governments can therefore encourage use of renewable energy sources such as biogas which can be generated and used at local levels ${ }^{[5]}$.

The strong growth in energy demand in Kenya provides excellent opportunities for private investors to invest in renewable energy power generation. ${ }^{[6]}$ work involved small scale biogas installations, constructed performing well. Such systems allow energy generation on site, thereby eliminating the need for energy intensive transport. The key factors that govern the productivity and stability of small scale systems are feedstock variability, retention time, temperature and acidity of the system. Day et al., ${ }^{[7]}$ found out that applying biogas technology to Kenyan small farms not only guarantees a reliable, renewable energy source, but also provides other benefits, such as cleaner household environments, better working conditions for housewives less time consumption.

\section{MATERIALS AND METHOD}

Status of Biogas use in Kenya: While biogas use in Kenya is still in its early stages of development, the technology has been present in the country for over 50 years. The first digester in Kenya was built in 1957 on a rural coffee farm. In the 1970s high fossil fuel prices led many countries to begin to research alternative energy sources, including the use of biogas as a source of energy in rural areas. During that time, more than 100 plants of varying types were sold in Kenya, mainly to large-scale farmers by a private entrepreneur. In addition, over the last fifty years, biogas technology has been promoted by national and international organizations (both Government and NGO) and they, together with trained Kenyan technicians have built hundreds of biogas digesters in the country.

The Renewable energy potential presented by available bio waste materials is yet to be fully exploited in spite of the growing interest in biogas production. When the technology is demand driven, there exists an opportunity for both governments and entrepreneurs to develop a feasible, commercial biogas programmed appropriate for the local setting ${ }^{[8-10]}$. Biogas technology has been advanced around the 
world as a renewable source of energy by various organizations such as government agencies, International organizations and Non-Governmental Organizations (NGOs) ${ }^{[11]}$.

The Kenya Ministry of Energy has put in place several promotional efforts and enabling frameworks aimed at promoting biogas use among other renewable energy resources. However, over the years, the penetration of the biogas technology in the country has been low and slow due to a number of reasons. According to a feasibility study, 'Promoting Biogas Systems in Kenya', commissioned by Shell international in 2007, a high proportion of the biogas digesters operated below capacity, were dormant or in complete disuse after construction. The report further indicated that only $30 \%$ of the 2,000 biogas plants earlier constructed were fully operational at the time of the study. A further survey, the Kenya Domestic Biogas users, 2014, revealed that Wood fuels still dominate energy consumption patterns firewood and charcoal account $90 \%$ of domestic energy supply despite high awareness of biogas option among the households. High awareness of biogas technology was apparent-over $90 \%$ but still with very low adoption rates by most farmers in Kenya.

To overcome this slow adoption of the biogas technology, the government has stipulated an implementation agenda aiming at promoting biogas by conducting adequate research to support the technology, developing training programmers, zero rating biogas plant equipment and creating awareness through public forums and energy centers. This together with efforts from other players has spurred growth of the biogas sector and there has been significant uptake of biogas as a fuel especially at the household level. To date, it is estimated that about 20,000 biogas units have been installed in the country. This is through the efforts of the Kenya Biogas Partnership Programmed which has installed 17,000 units across the country in 36 counties, 2000 units installed by private domestic biogas entrepreneurs and 1000 units done by Energy Centers (Regional Energy Centers established by the Ministry of Energy across the country).

Table 1: Number of installed biogas units in Kenya

\begin{tabular}{llll}
\hline Year & $\mathbf{2 0 0 5}$ & $\mathbf{2 0 1 2}$ & $\mathbf{2 0 1 5}$ \\
\hline Units installed & 500 & 1884 & $4000-16000$ \\
\hline
\end{tabular}

Table 2: Smaller commercial biogas plants installed in Kenya

\begin{tabular}{|l|l|c|}
\hline Place & place & (Capacity in MW) \\
\hline Dagoretti & Slaughterhouse waste & 0.03 \\
\hline Isinya & P. J. Dave Flower Farms Ltd(PPP) & 0.10 \\
\hline Keekonyoike & Slaughterhouse waste & 0.020 \\
\hline Kericho & James Finlay Ltd & 0.160 \\
\hline Kilifi & Pine Power Ltd & 0.150 \\
\hline Naivasha & Bio-joule Kenya & 0.340 \\
\hline Simbi Roses & Ereka Holdings Ltd (PPP) & 0.055 \\
\hline
\end{tabular}

Source: Energies, 2018

The collaboration of the government, through the Ministry of Energy, with other biogas stakeholders and players, has yielded several programmes and initiatives that have advanced biogas adoption. 


\section{RESULT AND DISCUSSION}

Biogas Technologies and Technology Dissemination: Biogas technology in Kenya has been earmarked as one of the main drivers towards the elimination of energy poverty in majority of rural households and to this end different biogas digester models are actively promoted. Initially, two types of biogas systems were promoted: the floating drum (Indian digester) and the fixed dome type (Chinese digester).

Later in the 1990s a low cost Tubular Plastic (TP) bio-digester developed in Colombia was also introduced and has been widely promoted especially in Western part of Kenya ${ }^{[3]}$ A number of Indian floating-drum plants and Chinese fixed-dome plants were installed particularly for public institutes, like schools and other education centers by private organizations often with foreign sponsors.

Assessing the sustainability of the biogas systems in Kenya is one of the topical issues driving the discussion on biogas development. According to a comparative analyses of the common biogas production systems in Kenya by linking the biogas energy with infrastructures of production ${ }^{[12]}$, it was observed that the tubular and the fixed dome digesters with respective cumulative multi criteria sustainability scores of $70 \%$ and $57 \%$ are the most sustainable with respect to animal manure as the predominant feedstock.

The presently promoted technologies in the Kenyan market is the Fixed Dome which has been continually improved. This include the Akut model, the Kenya Biogas Model (KENBIM) and the modified KENBIM which has been improved by cost reduction of the installation cost.

The bag biodigesters have been promoted in various models as designed by different private players and have taken different forms including the Flexi bag by Biogas International, the Bag System by TakaMoto and the Systema Bio system. Some of the bag digesters have been modelled as Plug flow biodigesters and others as semi-continuous biodigester.

Biogas Substrates: Most agricultural biowaste are wasted in the farms through burning or uncontrolled decay thus leading to nitrogen leakage and eutrophication in the surrounding water bodies as well as contributing to odour and greenhouse gas emission through release of volatile and unburnt hydrocarbons. But there is high potential for biogas in the country. Most households who have 2 or more cattle under zero grazing, or 4 or more cattle under semi zero grazing are technically eligible to benefit from biogas technology.

According to Ministry of Energy, the technical potential for biogas is highest in the high population density areas where zero grazing is practiced (Central Kenya, Kisii, Kericho, Meru, Western Kenya). Figure 1 shows areas across the country with dairy cattle population that indicate the potential for biogas. Wood fuel scarcity, increasing energy costs and pressure for land in the high potential districts mean that the benefits of biogas are becoming more apparent to eligible households

Biogas potential in Kenya has also been identified in Municipal waste, sisal and coffee production. The total installed electric capacity potential of all sources ranges from $29-131 \mathrm{MW}$, which is about 3.2 to $16.4 \%$ of the total electricity production. Other substrates like water hyacinth and molasses distillery waste have been found to be a good source of biogas ${ }^{[13,14]}$. 


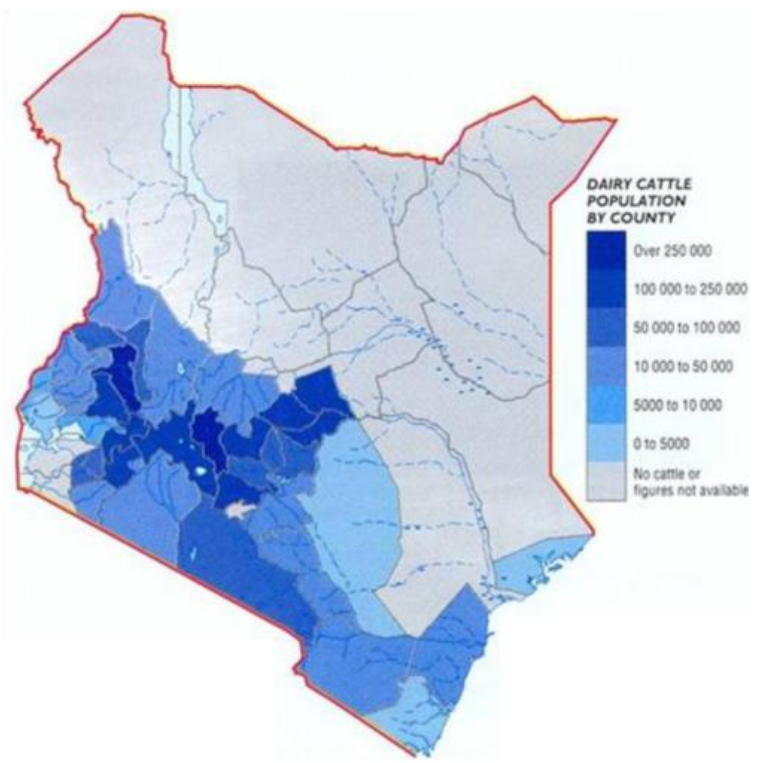

Figure 1: Areas with high density of zero grazed cattle population

Table 3: Potential Biogas substrates for energy generation

\begin{tabular}{|l|c|}
\hline Source & Energy Potential(GWh) \\
\hline Coffee & $12.6-147.6$ \\
\hline Chicken & $5.8-24.7$ \\
\hline Cut flowers & $2.4-7.6$ \\
\hline Tea & $2.7-7.8$ \\
\hline Sisal & $65.4-284.3$ \\
\hline Sugar & $18.6-42.8$ \\
\hline Milk & $1.4-7.2$ \\
\hline Pineapple & $9.6-26.6$ \\
\hline Municipal waste & $80.6-512.6$ \\
\hline Distillery & $1.8-14.9$ \\
\hline Meat & $0.09-0.6$ \\
\hline Pig & $1.6-3.8$ \\
\hline Vegetable & $0.02-0.2$ \\
\hline
\end{tabular}

Cost and Financing: Most biogas systems for Kenyan household go for KShs 75,000. Data on economic viability, payback period of the biogas plants was not available but results got from Uganda by Peter Nabusi et al. ${ }^{[15]}$ show that 1.17, 1.08 and 1.01 years for $8 \mathrm{~m}^{3}, 12 \mathrm{~m}^{3}$ and $16 \mathrm{~m}^{3}$ biogas plants, respectively. The positive net present values of $4500 \$, 7000 \$$ and $9500 \$$ for $8 \mathrm{~m}^{3}, 12 \mathrm{~m}^{3}$ and $16 \mathrm{~m}^{3}$ plants, respectively, show that biogas systems are economically viable. The annual interest rates at which households should borrow to invest in biogas systems and remain economically viable should not exceed $36 \%, 37 \%$ and $39 \%$ for $8 \mathrm{~m}^{3}, 12 \mathrm{~m}^{3}$ and $16 \mathrm{~m}^{3}$ plants. The viability of biogas is greatly affected by variation in operating and maintenance costs.

The team of Sara Ghaem et al. ${ }^{[16]}$ in their study, a hybrid power system consisting of PV (Photovoltaics) panels, a wind turbine and a biogas engine was proposed to supply the electricity demand of a village in Kenya. The average and the peak load of the village are around $8 \mathrm{~kW}$ and 
$16.5 \mathrm{~kW}$ respectively. The feasibility of using locally produced biogas to drive a backup engine in comparison to using a diesel engine as backup has been explored through a techno-economic analysis using HOMER (Hybrid Optimization Model for Electric Renewables). This hybrid system was compared with a single diesel based power system. The hybrid system integrated with the biogas engine as backup was better solution than using a diesel engine as backup. The share of power generation by PV, wind and biogas are 49\%, 19\% and 32\%, respectively. The LCOE (Levelized Cost of Electricity) of generated electricity by this hybrid system $(\$ 0.25 / \mathrm{kWh})$ was about $20 \%$ cheaper than that with a diesel engine as backup $(\$ 0.31 / \mathrm{kWh})$, while the capital cost and the total NPC (Net Present Cost) are about 30\% and $18 \%$ lower, respectively. Regarding $\mathrm{CO}_{2}$ emissions, using a biogas engine as backup saves 17 tons of $\mathrm{CO}_{2}$ per year compared to using the diesel engine as backup.

Legal, Institutional and Policy Framework: Claudius Da Costa Gomez 2013 ${ }^{[17]}$ describes the potential, requirements, risks, required general conditions and the prospects of biogas production. The necessity of effective government support is emphasized. Biogas has a special role to play in the scenario of the fundamental change of today's energy supply patterns because electricity and heat can be produced as and when needed. The Kenya Government's intended biogas upgrading methodologies, scientific and technical outcomes related to their biomethanation efficiency, challenges that have to be addressed for further development and incentives and feasibility of the upgrading concepts is detailed in the Research Review Paper by Angelidaki et al. ${ }^{[18]}$. Kenyans are facing both quality of life and livelihood challenges associated with sub-optimal sanitation, dependence on biomass energy, and decreasing agricultural productivity. To mitigate these livelihood challenges, the government needs a National Policy Framework, which encourages the uptake of biogas technology.

The government of Kenya acknowledges the role of energy in economic development and has made tremendous efforts to ensure that all Kenyans have access to affordable energy. The government 's effort in the adoption of the Biogas technology is well spelled out in the National Energy Sessional Paper of 2004 and in the Energy Act No.12 of $2006^{[19] .}$ In addition, in keeping with the Government's Economic Recovery Strategy for Employment and Wealth creation for the Republic of Kenya, Ministry of Energy and Petroleum, a draft National Energy Policy $24^{\text {th }}$ February 2014, was developed in order to spell out the aspirations of the government towards provision of quality, sufficient, cost effective, sustainable and affordable energy services for economic growth. This was further reviewed into the recently enacted Energy Policy 2018 and the Energy Act, 2019. The Act has several amendments to the repealed Energy Act intended to amalgamate the laws regulations relating to energy, to clearly outline the functions of both the national and the county government in relation to energy and to provide for the exploitation of renewable energy sources. The bioenergy strategy under development targets to Promote use of Biogas technology by households and institutions specifically through building capacity of service providers to increase their pool and quality of Service, investing in R\&D geared towards low cost biogas technologies, incentivizing households and institutions investing in biogas technology by offering tax rebates as well as increasing public awareness on the benefits and potential of biogas technology. The strategy was informed due to the fact that the current bio-energy production, conversion and utilization trends and patterns are still unsustainable with many households still relying on traditional biomass fuels to meet their cooking needs. These traditional fuels not only exacerbate climate change through deforestation and GHG emissions but also cause respiratory diseases.

In June 2008, Kenya's Vision 2030, the country's development blue print for economic transformation to an industrialized middle-income country was launched by the President. It is anchored on three pillars: social, economic and political. The need for energy security became urgent drivers for alternative energy which called for re-assessment and update of the country's policy and strategy. Under vision 2030 the government promotes development of renewable energy as an alternative source of 
energy and includes energy from solar, wind, biogas as well as development of bio-energy including bio-ethanol, bio-diesel and biogas value chains. To encourage investment and energy generation from renewable resources, Feed in Tariff (FiT) Policy was introduced in 2008 and revised in 2010 and 2012 respectively. This policy is aimed at attracting private sector investments in electricity generation from Renewable energy sources which include wind power, biomass, small hydro, solar, biogas and geothermal. The feed-in tariff allows power producers to sell and obligates the distributor to buy on priority basis all renewable energy sources generated electricity at a pre-determined fixed tariff for a given period of 20 years. The Feed-in Tariff for biogas energy aims at generation of electricity from agricultural and municipal wastes.

Table 4: Feed-in tariffs (2012) for renewable energy projects in Kenya

\begin{tabular}{|l|l|l|l|l|l|}
\hline Plant type & $\begin{array}{l}\text { Installed } \\
\text { capacity } \\
\text { (MW) }\end{array}$ & $\begin{array}{l}\text { Standard } \\
\text { FIT } \\
(\mathrm{US} \$ / \mathrm{kWh})\end{array}$ & $\begin{array}{l}\text { Scalable portion } \\
\text { of the tariff }\end{array}$ & $\begin{array}{l}\text { Minimum } \\
\text { capacity } \\
\text { (MW) }\end{array}$ & $\begin{array}{l}\text { Maximum } \\
\text { capacity } \\
\text { (MW) }\end{array}$ \\
\cline { 1 - 5 } Wind & $0.5-10$ & 0.1100 & $12 \%$ & 0.5 & 10 \\
\hline Hydropower & 0.5 & 0.1050 & $8 \%$ & 0.5 & 10 \\
\cline { 2 - 6 } & 10 & 0.0825 & & 0.5 & 10 \\
\hline Biomass & $0.5-10$ & 0.1000 & $15 \%$ & 0.2 & 10 \\
\hline Biogas & $0.2-10$ & 0.1000 & $15 \%$ & 0.5 & 10 \\
\hline Solar (grid) & $0.5-10$ & 0.1200 & $8 \%$ & 0.5 & 10 \\
\hline Solar (off-grid) & $0.5-10$ & 0.2000 & $8 \%$ & & \\
\hline
\end{tabular}

Source: National Energy and Petroleum Policy 2015

The energy sector has been identified as a key sector to contribute in achieving the Nationally Determined Contributions for the country, both in mitigation and adaptation, and adoption of RE is the main route of achieving this. Biogas has particularly a big role because it contributes to both the energy sector and waste management sector. The Action Agenda for the SE4ALL framework in Kenya has promotion of RE technologies as a key agenda.

The Ministry of Energy, through its Renewable Energy (RE) Directorate has the responsibility of promoting RE technologies through research, capacity building and formulation of Policies and Laws that provide enabling environment for efficient and sustainable production, distribution, marketing and use of RE technologies. Significant improvement in penetration of biogas technologies has been achieved in partnership with other private sector players and development partners. Energy and Petroleum Regulatory Authority (EPRA) is responsible to facilitate access to efficient and sustainable energy through enabling regulation geared towards better quality of life in Kenya.

Research to estimate the economics of biogas plants identify the factors affecting the adoption of biogas technology in progress At Kenya Industrial Research and Development Institute. The key stakeholders of the biogas plant are farmers. The most feasible size for digester is $1 \mathrm{~m}$ diameter and $1 \mathrm{~m}$ height because 
it fulfills the needs of an average family. However, small farmers with plant size of $4 \mathrm{~m}^{3}$ benefit more than large farmers. Moreover, biogas adoption is not only financially feasible but environment-friendly as well. We conclude that biogas technology can be popularized by developing effective motivation strategies such as awareness through public service advertising, through print and electronic media and by adoption of models of biogas plants best suited to the conditions of rural people in Kenya. This further highlights the demand for the required policy framework to promote such renewable energy adoption technologies by local government and agricultural institutions, researchers, and policy makers. Large scale adoption for biogas technology include establishing National Institutional framework, increasing research and development, education and training and providing loans and subsidies and major policy shift in the Energy sector. Kenya Biogas an umbrella body be formed with this mandate: certification and standards, regulation and licensing, lobbying and advocacy, research and development, education and training, funding and financing has been taking an active role.

Kenya National Domestic Biogas Program (KENDBIP) 2009-2018 has been instrumental in promoting biogas in the country. The programme was part of the Africa Biogas Partnership Programme (ABPP) which is a partnership between the Dutch government, Hivos and SNV Netherlands Development Organization.ABPP supportsnational programmes on domestic biogas in five African countries namely Kenya, Uganda, Tanzania, Ethiopia and Burkina Faso.The programme funded by the Dutch Government set out to promote the use of small scale bio-digesters geared towards phasing out dependence on fuelwood and charcoal for cooking by households. KENDBIP aimed at reaping the environmental benefits of reducing carbon emissions through substituting traditional cookstoves for biogas stoves as well as utilization of bio-slurry which is the by-product of biodigestion as fertilizer and replace the conventionally used chemical fertilizers. During Phase 1 (2009-2013) 11,529 plants were constructed against the target of 11, 690 biogas plants. Since its inception in 2009 and estimated 15,000 biodigesters have been built across Kenya with over 100 masons starting their own business entities thus building the local economy. Other impacts and benefits associated with the project include: 15,140 smoke-free kitchens, 333,500 $\mathrm{tCO}_{2}$ reduced, 202,000 tons of wood saved and 14,200 productive slurry users.

The private sector has partnered with government. Keekonyokie, a privately owned company that began its operations in 1982 runs an abattoir that slaughters about 100 cows per day to meet the meat demand in Nairobi and its environs. In 2008, the company constructed two 20-foot-deep biogas digesters to help manage the slaughterhouse waste while producing clean and affordable biogas for the plant. Within a short time, the biogas produced from the digesters was more than the company could absorb. Kenya Climate Innovation Centre (KCIC) and Kenya Industrial Research and Development Institute (KIRDI) offered financial and technical support respectively and is now producing affordable biogas and packaging it for distribution.Promotion of biogas as a fuel has further been achieved through the establishment of the Domestic Biogas Stoves Specification. The specifications for the domestic biogas stoves are covered under the Kenya Standard KS2520:2014. This Kenya Standard covers construction, operation, safety requirements and methods of test for stoves intended for use with biogas.

Challenges of Biogas Technology Development in Kenya: The implementation of large-scale biogas technology in Kenya has continued to be hindered or slowed by; economical, technical, social-cultural, institutional, political and information - oriented constraints. Weak linkages of institutions and stakeholders developing and promoting biogas technology in the area have undermined promotion strategies in the area. There is no coordinating body to harmonize ideas for promotion of biogas technology hence the institutions act independently. The existing institutions, though acting independently, do not have enough capacity to play their roles. Key institutions have inadequate human personnel and limited access to finances to carry out their devolved functions. In addition, the 
legislations do not uphold the technology. Therefore, there is need to come up with a national Biogas institution to Coordinate overall devolved activities of the biogas sector.

Benjamin et al. ${ }^{[20]}$ Investigated the benefits and challenges facing an innovative biogas system being commercialized in Kenya by the International Fund for Agricultural Development (IFAD) and Biogas International. From 2011 to 2014, IFAD and Biogas International have distributed 500 flexi-biogas system (FBS) units to rural Kenyan households. FBS devices have the potential to address climateenergy-agriculture vulnerabilities and also generate income and improve social resilience and although the benefits of FBS adoption cut across dimensions, scales, and sectors, the policies needed to support them must be concomitantly synergistic and multidimensional.

The use of biogas is evidence that it is a viable energy resource for household cooking. Research literature has identified a number of demand side market barriers to the household use of clean cooking fuels. The combination of these factors, which are social, economic and political-has contributed to the continued dependence on primitive biomass fuels in the majority of households in sub-Saharan Africa. While the socioeconomic market barriers to clean cooking fuels limit demand considerably, an active government can adopt a range of strategies to overcome these barriers. At the national level, governments must strengthen the institutional framework that governs household energy services to enable informed policy to be identified and implemented. National clean cooking fuel initiatives must offer both short- and long-term strategies for addressing the household energy crisis in sub-Saharan Africa. ${ }^{[8]}$.

Jecinta Mwirigi et al. ${ }^{[21]}$ examines the socioeconomic constraints to adoption of biogas in Sub-Saharan Africa and explored factors that could enhance adoption of the technology. These include standardization and quality control, as well as an approach of integrated farming using biogas and slurry. They recommended mobilization of local and external funds to promote biogas, use of ready to use funds such as the Clean Development Mechanisms in overcoming the initial construction costs of biogas units, and formation of user and disseminator associations to reduce costs by joint procurement and linkage to finance to facilitate environmental management and economic development in Sub-Saharan Africa. They employed the ex-post-facto social survey research design for Socio-economic constraints to adoption and sustainability of biogas technology by farmers in Nakuru Districts, Kenya. The target population was the 9466 farmers in Nakuru districts. Selection of the two hundred farmers was through stratified proportionate random sampling procedure in order to represent the various plant designs and farmer populations in the respective administrative divisions. Data collection was through a pre-tested interview schedule, two types of questionnaires and a personal observation schedule while analysis was through descriptive and inferential statistics (Chi-square) by use of SPSS software. The analysis revealed that while a farmer's socio-economic status significantly influenced the decision to adopt the technology, it did not influence the sustainability of the constructed plants. While the potential of the technology to flourish in the study area is high, its promotion is necessary. Remedial action calls for a multi-disciplinary approach by all stakeholders that include governmental and non-governmental organizations, technology experts, farmers as well as research and training institutions. Adoption constraints that include awareness creation, land tenure security, financial capital, livestock improvement and research and policy review need to be addressed. Technical constraints that have slowed growth of biogas uptake have been identified as inadequate capacity for installation, maintenance and operations

The importance of Biogas towards meeting the energy needs in rural areas is a dynamic approach to desertification challenge. Lack of structured information is deemed to be one of the major bottlenecks for successful adoption of biogas technology. There is therefore a need for a concerted and coordinated 
multi-faceted approach to establish a locally designed knowledge exchange service. Such a service can provide the necessary biogas technology information that can inform the decision makers besides facilitating in monitoring and evaluation exercises, promotion and raising awareness pertaining to the accruing benefits and resultant impacts. A database system containing important information and data on biogas technology and feedstock such as agricultural residues and their biogas potential can serve as a one stop source of information for donor agencies, policy makers, consumers, local population as well as the academia. ${ }^{[22]}$.

Limited success in promoting improved energy sources, such as biogas, in rural areas of developing countries has been partly blamed on insufficient understanding of household energy use patterns. There is need to assess the costs of biogas generation, as well as the economic potential of biogas as an alternative in addressing both energy and food security challenges. By investing in biogas plants, households could save time and energy, and have a supply of slurry that can be used as fertilizer in agricultural production. A cost-benefit analysis of biogas plants yields positive net present values for households collecting their own energy sources. Household digesters are cheap, easy to handle, and reduce the amount of organic household waste.

The size of these digesters varies between 1 and $150 \mathrm{~m}^{3}$. The common designs include fixed dome, floating drum, and plug flow type. Even higher net present values are obtained for households purchasing all of their energy needs; these households stand to gain significantly from the financial benefits of energy cost savings with biogas technology. Results are highly dependent on slurry being effectively used as a source of fertilizer and on the price of the replaced energy source.

Thus the promotion of slurry use as fertilizer must be an integral part of a successful biogas programme. However, when analyzed over long periods there is depreciation and investment risks increase ${ }^{[23]}$. Diversification on the type of substrate to be used has been done by Alfa et al. ${ }^{[24]}$ who demonstrated that Lemon grass produced less volume but better quality biogas compared to Cow dung and Poultry droppings. Ester Kiarie ${ }^{[25]}$ investigated on sisal as the biogas feedstock and found that the sustainable and economic factors necessary for biogas production was found to have a direct effect on the sisal utilization and also influenced the energy demand and consumption at the Plant.

Kenyans are facing both quality of life and livelihood challenges associated with suboptimal sanitation, dependence on biomass energy, and decreasing agricultural productivity. To mitigate these livelihood challenges, the government needs a national policy framework, which encourages the uptake of biogas technology. However, despite expectations of improved health and livelihood outcomes from biogas technology, rigorous impact evaluations of existing biogas interventions in Kenya do not exist.

Data on the impact of biogas technology adoption on indoor air pollution (IAP) health symptoms on households is necessary. What is true is that biogas adopters spent less time per year collecting fuel energy and shows the potential for small-scale biogas to improve human capital formation through better health, which is one the major targets of the UN Sustainable Development Goals. Others areas include to (a) adopt integrated policy approaches and enhance stakeholder collaboration; (b) raise awareness of the benefits of clean cooking with biogas; (c) facilitate access to funding and establish appropriate economic incentives; (d) implement quality assurance mechanisms; (e) enhance research, development, and technical capacity ${ }^{[26]}$.

The role of technological innovation system (TIS) in fostering technology functional buildup of TIS shapes technology diffusion levels in least-developed country settings. A comparative analysis of the biogas TIS shows patterns of accumulation of TIS functions that may determine rates of technology 
diffusion. To ensure accelerated diffusion of RETs, policy attention should be paid to improving the functional performance of TIS. ${ }^{[26]}$.

\section{CONCLUSION}

The impact of the biogas, in Kenya is early to show, but schools, hospitals and local communities have all expressed interest, citing the high cost of electric power as a major challenge. Interest ranged from using the gas for: cooking, powering a generator to produce electricity. However, the uptake of the biogas technology in Kenya is quite an expensive enterprise. Limited trained personnel and service providers, remain key challenges. For the poor households, the starting capital of around Shs.60,000 is high but the few run biogas plants have shown success. The need to benefit from Kenyan biomass resources is fully justified by low electric distribution, alarming deforestation and the pressing use of clean energy and sustainable environment. Considering the role, importance and contribution of biogas technology to the welfare the communities, especially those with low income and present dissemination rate, there is a wide gap to mitigate. Besides, the biogas dissemination will have to go beyond some hitches like high investment cost, and security issues together with pilot phase grievances to ensure that marketable biogas technology has been put in place. There is a need to fully engage and speed up dissemination of biogas digesters by designing specific policies, full support and promotion of anaerobic digestion technology. Going forward, Kenya has vast untapped potential for the utilization of various different organic materials for the production of renewable, decentralized power. In the coming years biogas will play a significant role in the Kenya's power generation mix.

\section{REFERENCES}

1. A.Whiting, A. Azapagic, Life cycle environmental impacts of generating electricity and heat from biogas produced by anaerobic digestion. Energy,2014,70, 1.181-193

2. G.Austin, G. Morris, Biogas Production in Africa. In: Janssen R., Rutz D. (eds) Bioenergy for Sustainable Development in Africa. Springer, Dordrecht, 2012.

3. J.K.Kiplagat, R.Z. Wang, T.X. Li, Renewable energy in Kenya: Resource potential and status of exploitation Renewable and Sustainable Energy Reviews, 2011, 15,6, ,2960-2973 https://doi.org/10.1016/j.rser.2011.03.023

4. Ministry of Energy Act 2013.

5. Ruth Kwamboka Momanyi, Annie Hilda Ong'ayo, Okeyo Benards, Social-Economic Factors Influencing Biogas Technology Adoption among Households in Kilifi County- Kenya. Journal of Energy Technologies and Policy www.iiste.org ISSN 2224-3232 (Paper) ISSN 2225-0573 (Online)2016,6, 6

6. Linus Naik Zenebe Gebreegziabher Vianney Tumwesige Bedru Babulo Balana Jecinta Mwirigi Greg Austin (2014) Factors determining the stability and productivity of small scale anaerobic digesters. Biomass and Bioenergy,2014, 70,51-57https:// doi.org/ 10.1016/j. biombioe. 2014.01.055

7. D.L.Day, T.H. Chen, J.C. Anderson, M.P. Steinberg,Biogas plants for small farms in Kenya. Biomass,1990, Volume 21, Issue 2, 1990, Pages 83-99 https://doi.org/10.1016/01444565(90)90051-K

8. I.Rutamu, Low cost biodigesters for zero grazing smallholder dairy farmers in Tanzania. Livestock Research for Rural Development, 1999, 11(2). 
9. Biogas for Better Life, An African Initiative, 2007, URL https://www.biogasafrica. Org

10. A.T.Abbey, Biogas in Uganda: A new experience. Leisa Magazine, 2005, 21(1). URL http://www.leisa. info.

11. S.Rai, Biogas sector partnership (BSP), Nepal, 2009. Retrieved from www.ashden.org.

12. Nzila Charles, Jo Dewulf, Henri Spanjers and David Tuigong, Multi criteria sustainability assessment of biogas production in Kenya, Applied Energy, 2012, 93, DOI:10.1016/ j. apenergy .2011 .12 .020

13. P.Njogu, R. Kinyua, P. Muthoni and Y. Nemoto, Biogas Production Using Water Hyacinth (Eicchornia crassipes) for Electricity Generation in Kenya. Energy and Power Engineering, 2015, 7, 209-216. http://dx.doi.org/10.4236/epe.2015.75021

14. J.H.Y.Katima, Production of biogas from water hyacinth: Effect of substrate concentration, particle size and incubation period. Tanz. J. Sci. 2001,27: 107-119

15. Peter Nabusiu Walekhwa, Drake Lars, Johnny Mugisha (2014), Economic viability of biogas energy production from family-sized digesters in Uganda. Biomass and Bioenergy, 2014, 70,2639, https://doi.org/10.1016/j.biombioe.2014.03.008

16. Sara Ghaem Sigarchian, Rita Paleta, Anders Malmquist, André Pina 2015, Feasibility study of using a biogas engine as backup in a decentralized hybrid (PV/wind/battery) power generation system - Case study Kenya. Energy, 2015,90,Part 2 , 1830-1841, https:// doi.org/ 10.1016/ j.energy.2015.07.008

17. Claudius Da Costa Gomez, Biogas as an energy option: an overview.The Biogas Handbook. Science, Production and Applications, Woodhead Publishing Series in Energy 2013, Pages 116

18. Irini Angelidaki, Laura Treu, Panagiotis Tsapekos, Gang Luo, Stefano Campanaro, Henrik Wenzel, Panagiotis G. Kougiasa (2018), Research review paper. Biogas upgrading and utilization: Current status and perspectives. Biotechnology Advances,2018,36,2,452-466, https://doi.org/10.1016/j.biotechadv.2018.01.011]

19. Benjamin K.Sovacool, Matthew Kryman, Taylor Smith, Scaling and commercializing mobile biogas systems in Kenya, 2015, A qualitative pilot study. Renewable Energy Volume 76, Pages $115-125$

20. Jecinta Mwirigi, Bedru Babulo Balana, Johnny Mugisha, Peter Walekhwa, Rethabile Melamu, Sylvia Nakami, PaulMakenzi (2009) Socio-economic hurdles to widespread adoption of smallscale biogas digesters in Sub-Saharan Africa: A review. Biomass and Bioenergy,2009,70,1725. https://doi.org/10.1016/ j.biombioe. 2014. 02.018

21. Janet Olowoyeye (2013) Comparative Studies on Biogas Production using Six Different Animal Dungs, Journal of Biology, Agriculture and Healthcare,2013,3, 15, 7

22. S.G.Gwavuya, S. Abele, I.M. Barfuss, J. Müller, J. (2012), Household energy economics in rural Ethiopia: A cost-benefit analysis of biogas energy. Renewable Energy.2012,48,202-209. https://doi.org/10.1016/j.renene.2012.04.042

23. M.S.Alfa, O. Dahunsi, O.T. Iorhemen, C.C. Okafora, S.A. Ajayid,S.A. (2014) Comparative evaluation of biogas production from Poultry droppings, Cow dung and Lemon grass. Bioresource Technology,2014,157,270-277.https://doi.org/10.1016/j.biortech.2014.01.108 
24. Esther Kiarie, Biogas as A Potential Alternative Source of Energy for Industrial Sector: Case Study of Kilifi Sisal Plantation Biogas Plant. International Journal of Advanced Research and Publications,2019, ISSN: 2456-9992 Volume 3 Issue 7, July 2019 www.ijarp.org 30

25. Alice Karanja, Alexandros Gasparatos, Adoption and impacts of clean bioenergy cookstoves in Kenya. Renewable and Sustainable Energy Reviews,2019,102,285-306, https: //doi.org /10.1016/j.rser.2018.12.006

26. Aschalew Demeke Tigabu Frans Berkhout Pietervan Beukering (2015), The diffusion of a renewable energy technology and innovation system functioning: Comparing bio-digestion in Kenya and Rwanda. Technological Forecasting and Social Change.2015, 90, Part A, 331-345. https://doi.org/10.1016/j

\section{* Corresponding Author: Lumadede H.M.*}

Energy Research Division, Department of Research Technology and Innovation, Kenya Industrial Research \& Development Institute, P. O. Box 30650-00100, Nairobi, Kenya

Online date of publication: 23.07.2021 